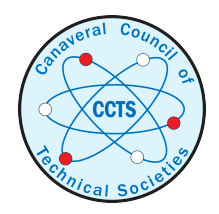

Mar 7th, 8:00 AM

\title{
A Systematic Approach for the Analytical Analysis and Prediction of the Yield From Liquid Propellant Explosions
}

\author{
E. A. Farber \\ Professor \& Research Professor of Mechanical Engineering, The University of Gainseville, Florida \\ J. H. Deese \\ Chief Facilities Technology Office, NASA
}

Follow this and additional works at: https://commons.erau.edu/space-congress-proceedings

\section{Scholarly Commons Citation}

Farber, E. A. and Deese, J. H., "A Systematic Approach for the Analytical Analysis and Prediction of the Yield From Liquid Propellant Explosions" (1966). The Space Congress ${ }^{\circledR}$ Proceedings. 5.

https://commons.erau.edu/space-congress-proceedings/proceedings-1966-3rd/session-11/5

This Event is brought to you for free and open access by the Conferences at Scholarly Commons. It has been accepted for inclusion in The Space Congress ${ }^{\circledR}$

Proceedings by an authorized administrator of Scholarly Commons. For more information, please contact commons@erau.edu.

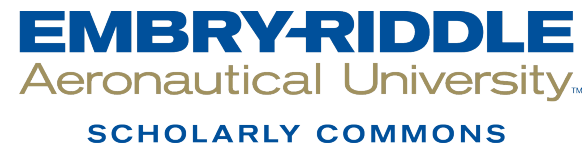


A SYSTEMATIC APPROACH FOR THE ANALYTICAL ANALYSIS AND

PREDICTION OF THE YIELD FROM LIQUID PROPELLANT EXPLOSIONS

\author{
Dr. E. A. Farber, Professor \& Research Professor \\ of Mechanical Engineering \\ The University of Florida \\ Gainesville, Florida
}

Mr. J. H. Deese, Chief

Facilities Technology office

NASA

John F. Kennedy Space Center, Florida

\section{Summary}

This paper presents a systematic approach by which the expected yield from liquid propellants can be predicted and furthermore gives an insight into the physical phenomena involved.

The yleld potential and the mixing function can be determined allowing for the type of propellants, their relative proportions, the reaction rates between the components depending upon mixture composition, the heat transfer rates between the components and the propellants and the surroundings, the mode of failure and the resulting mixing characterfstics, and the ignition and reaction delay times.

Combining the above information into seven charts as presented leads to a systematic analytical determination of the expected yield.

\section{Introduction}

In an effort to assess and minimize the hazards from liquid propellant explosions as a result of missile failures to astronauts, launch support personnel, launch faclities and surrounding structures it is of utmost importance to be able to predict the most probable expected yield.

An approach, considering the overal1 characteristics of Ilquid propellant explosions, to predict the most probable yield, the most probable spil1, probability distributions, confidence regions, confidence limits, etc. by means of a mathematical model was presented earlier 1,2 by one of the authors of this paper. The method described there, accomplished the ultimate goal of leading to a valid prediction procedure of yield, spil1, etc. of 1iquid propellant explosions, it did not provide an inslght into the physical phenomena producing this yield, spil1, etc.

The present paper suggests a more fundamenta 1 approach to this problem by considering the physical phenomena in detail which go into producing the most probable yield, spill, etc. This approach therefore can, through understanding of the physical processes and phenomena, provide the information necessary to control these processes.

The approach presented here is referred to by the authors as the "Seven Chart Approach" since the procedure can be summarized in seven charts, constituting a complete, well planned program, outlining the necessary steps to be followed.

Furthermore, the "Seven Chart Approach" uses presently available information regarding these poorly understood phenomena producing the liquid propellant explosion yield, points out where more theoretical and experimental work is needed and what information it should provide. In this manner an ideal balance is obtained between theory guiding the experimental work and the results from the experiments modifying the theory. For these reasons this procedure is able to reach the desired goals along a most direct route in the shortest possible time and at minimum cost.

Previous investigations $1,2,3,4,5$, both theoretical and experimental, through their results suggest that the actual phenomena producing the yield in liquid propellant explosions can be divided into groups which lend themselves to separate study, both theoretical and through small scale experimentation.

For the purposes of the "Seven Chart Approach," suggested here for the prediction of the most probable yield, etc. for liquid propellant explosions, the problem is divided into three such groups of phenomena which can be studies separately but when combined allow the desired prediction. The groups revolve around

I. The Yield Potential Function

II. The Mixing Function

III. Delay and Detonation Times and allow the incorporation of the basic characteristics of the particular prope1lants involved, of the missile design configuration, and of the mode of failure.

The yield potential function (I) is basically controlled by chemical kinetics, the mixing function (II) by the principles of hydrodynamics modified by heat transfer, and the delay and detonation times (III) by characteristic functions for some propellants such as hypergolics or by random processes for others.

The separate studies can be combined by taking the yield potential, when expressed as a time function, and multiplying it by the mixing function to obtain the expected yield at any time after the start of the failure or after the mixing has begun. This mixing function will be different for different modes of failure and missile 
configurations.

The actual expected yield can be determined by superimposing the delay and detonation times upon the above obtained expected yield function, either as a fixed value where applicable or as a statistically most probable value with proper confidence limits. These delay and detonation times are characteristics of the propellants such as hypergolics, cryogenics, etc., modified by the propellant quantities, missile configuration, modes of failure, etc.

The total procedure can be summarized, with the seven charts supplying the necessary information, as the relationship

$$
\begin{aligned}
& y=\left(y_{p} \cdot x\right)_{t *} \\
& \text { where } y \text { expected yield at time } t^{*} \\
& \\
& y_{p} \text { yield potential at time } t^{*} \\
& x^{*} \text { most probable detonation } \\
& \text { time }
\end{aligned}
$$

The development of the seven charts follows: Conditions were assumed so that quantitative results could be calculated for cases which were investigated experimentally and for which results are reported in literature. ${ }^{4}$ This gives more meaning to the procedure suggested and allows comparison of results obtained by the "Seven Chart Approach" with actual test results. The approach would be the same if other initial conditions, propellants, or configurations were used.

\section{The Yield Potential Function}

The yield potential function for any propellants or combinations of them as a function of time can be obtained from theoretical considerations in four steps as follows :

\section{Maximum Theoretical Energy Release (Chart 1)}

The maximum amount of energy which can be released from any particular liquid propellant fuel-oxidizer mixture can be calculated employing the basic laws of chemical kinetics.

Fig. $1 \mathrm{~A}$ and $1 \mathrm{~B}$ (in greater detail) show the results from such calculations for a three component propellant mixture, $\mathrm{LO}_{2} / \mathrm{LH}_{2} / \mathrm{RP}-1$.

The upper curve in these figures is the result of the three component mixture $\mathrm{LO}_{2} / \mathrm{LH}_{2} / \mathrm{RP}-1$, with the ratio of $\mathrm{LH}_{2}$ to $\mathrm{RP}-1$ held constant. In arriving at the numerical values it was assumed that al1 the $\mathrm{LH}_{2}$ always reacts, and as much of the $R P-1$ as can be supplied with $\mathrm{LO}_{2}$. Atmospheric oxygen could also be included if desired without any particular difficulty.

The lower curve is the result of a two component mixture $\mathrm{LO}_{2} / \mathrm{RP}-1$, again presented here without atmospheric oxygen contribution.
This curve is applicable to a two component mixture or could be considered the condition after all the $\mathrm{LH}_{2}$ of the three component mixture has evaporated.

Thus any three component $\mathrm{LO}_{2} / \mathrm{LH}_{2} / \mathrm{RP}-1$ mixture will have its starting point on the upper curve and will, due to evaporation of both the $\mathrm{LH}_{2}$ and the $\mathrm{LO}_{2}$, follow a path from the upper curve to the lower curve and then along the lower curve toward the origin, this is if reaction does not occur somewhere along this path terminating this process. The actual path depends upon the changes in the relative quantities of each component present. Two such paths are shown in Fig. $1 \mathrm{~A}$ and in more detail in Fig. 1B. How they are calculated will be explained later, but it might be mentioned at this time that they are for a mixture which was actually used in field experiments. ${ }^{4}$ One path assumes that the system is thermally isolated from the surroundings and the other path that maximum thermal interaction between the system and the surroundings occurs.

That the two paths are not as much different as might be expected indicates that the effect of the surroundings is minor.

\section{Yield Potential as a Function of Oxidizer to Fuel Ratio (Chart 2)}

The explosive yield of the liquid propellants will depend not only on the quantity of energy released, but also upon the rate at which this energy is released. Because of lack of information as to the variation in the reaction rates as a function of the propellant composition it was assumed for these calculations that the reaction rate remains essentially constant throughout the $\mathrm{LO}_{2}$ /Fue 1 ratios under consideration here.

With this assumption, which can however be replaced by reaction rate information as soon as it becomes available, and the information of Fig. 1, the yield potential can be calculated and normalized in terms of the theoretical maximum. The results are presented in Fig. 2.

\section{Mass-Fraction Time Relationship for $\mathrm{LH}_{2}$}

To be able to determine the actual paths as previously discussed and shown in Fig. $1 A, 1 B$, and 2 it is necessary to know the $\mathrm{LH}_{2} / \mathrm{LO}_{2}$ ratio and its variation. This is easiest obtained from calculations of the quantities of $\mathrm{LH}_{2}$ and $\mathrm{LO}_{2}$ present at any time.

The calculations are more or less standard involving the principles of thermodynamics and heat transfer but are very long and tedious. They involve simultaneous heat balance and heat transfer relationships with the proper heat transfer coefficients which allow, through step by step and iterated calculations, the estimation of the quantities of cryogenics vaporized, escaping or again condensed in the mixture, the quantities of fuel and oxidizer frozen and portions 
remelted, etc. Some simplifying assumptions were made wherever it seemed advantageous in reducing the large amount of computations without appreciably affecting the results. Where quantities were encountered which had the same order of magnitude, but the opposite sign and were relatively small, they were sometimes cancelled against each other. These actions helped tremendously in reducing the scope of the necessary computations. Contact area variations based upon mixing studies both at the University of Florida in connection with the study of explosive hazards of liquid propellants and information found in literature were used in the heat transfer equations together with the best available heat transfer coefficients to obtain the mass-fractions for $\mathrm{LO}_{2}$ and $\mathrm{LH}_{2}$.

The information needed and used aside from that supplied by supporting studies at the University of Florida are referenced in Table I but only the results from the actual calculations can be presented here because of the severe space limitations. The results are presented in Fig. $3 \mathrm{~A}$ and $3 \mathrm{~B}$.

Table I

Iist of Literature References Used in Support of the Calculations for the Results Presented In Fig. 1A through 3B

SUBJECT

REFERENCES

Average Chemical Formulae for Kerosene, RP-1

$6,16,17,19$

Average Heat of Combustion for Kerosene

Heat of Combustion for Hydrogen

Propellant Proportion used in Heat Transfer Calculations

Lan/RP-1 Contact Area versus

Time Data for $\mathrm{LO}_{2} / \mathrm{RP}-1$ Analogy

Film Coefficients for LAN/RP-1 Interface

Film Coefficients for $\mathrm{LN}_{2} / \mathrm{LH}_{2}$ Interface and $\mathrm{LN}_{2} / \mathrm{LH}_{2}$ Contact Area versus Time Data for $\mathrm{LO}_{2} / \mathrm{LH}_{2}$ Analogy

Latent Heat of Evaporation for $\mathrm{H}_{2}$ and Specific Heat for $\mathrm{GO}_{2}$

Specific Heat for L JP-1 to simulate $R P-1$

Latent Heat of Evaporation for $\mathrm{O}_{2}$

Latent Heat of Fusion

for $\mathrm{O}_{2}$
Approximation of Latent Heat

of Fusion for RP-1

Approximation of Specific Heat of Solid Kerosene

$13,14,15$

4. Yield Potential - Time Relationship (Chart 4)

Since in the method for the calculation of the yield potential - oxidizer to fuel ratio relationship time $t$ was the common variable used it is easy to put a time scale right on the paths as shown. Fig. 1B.

With these time scales right on the paths of Fig. 1B, these curves can be replotted giving the yield potential versus time relationship as seen in Fig. 4. These curves represent the theoretical maximum yield which could be obtained at any time $t$ from the above propellants due to the quantities of the constituents present at that time. One curve again represents the yield potential for the isolated system and the other for the system which has the maximum theoretical thermal interaction with the surroundings.

Since the curves of Fig. 4 give the yield for propellants when perfectly mixed to produce maximum yield, these results must be modified by the mixing function, the actual amounts (fraction of the maximum amount) which are mixed at any time $t$.

\section{The Mixing Function (Chart 5)}

While the Yield Potential function as calculated above for a specific case established the actual quantities of the various constituents present and the maximum theoretical yield, if all these constituents are mixed most effectively, it does not give any information as to the actual degree of mixing of the constituents.

For example, at time 0 when the constituents just begin to mix, none of them are actually mixed and therefore an explosion could not be produced. Thus at time 0 the mixing function is 0 while the yield potential function is near its maximum. The product of the yield potential and the mixing function at time 0 gives the true or expected yield. The mixing function is essentially a hydrodynamic function, however complicated by high rates of heat transfer. This makes the analytical approach difficult, and at least to start with an experimental approach for determining this function more promising. This is true especially since questionable assumptions are not involved.

Four methods have been developed in connection with the overall systematic approach presented in this paper and to implement its execution. These four methods allow the detailed study of the mixing process and phenomena producing the mixing function of liquid propellants and have been used with great success. In preliminary studies, often applying two methods to. the same experiment, these methods have independently 
produced results which are in excellent agreement.

The detailed description of these methods and the various methods of analysis and the results obtained by them are beyond the scope of this paper, but since they implement the approach suggested in this paper they are briefly mentioned. They are the

\section{A. Film Analysis}

A high speed photographic technique giving by use of mirrors a three dimensional picture of the mixing process on the same film frame. Special analysis of these frames as to mixing profile, mixing volume, and turbulence factor allow the determination of contact area and degree of mixing.

\section{B. Wax Cast Analysis}

By use of hot wax and cold liquids the mixing process can be "frozen" at different stages of the mixing by varying the hot and cold temperatures. The "frozen" state of the mixing process can then be studied at any time later. These casts can be analyzed as to profile, outside area by projection or coating methods, they can be serially sectioned to give the total contact area, turbulence factors (total contact area over profile area), etc.

\section{Vibration Mixing Analysis}

This method consists of mounting a particular configuration on a vibration table, simulating the various propellant components by particles of different color, size, density, shape, etc., and after removing partitions partially or completely shaking the system. The components will mix and the degree of mixing can be periodically checked at desired locations and prescribed intervals.

\section{Thermocouple Grid Analysis}

This method of analysis employs a three dimensional grid of fine thermocouples with each junction being monitored continuously. The traces give information regarding the mixing front, the degree of mixing at a particular point, the degree of turbulence at a point, the location of the point or points of ignition, the time delay from the start of mixing (or time of failure) to ignition, the propagation of the reaction front, the propagation of the shock front, the separation of the shock front from the reaction front, etc.

Results from the above methods can be correlated and compared easily by simultaneously applying the different methods of analysis to the same experiment. These methods provide information needed for the better understanding of the mixing phenomena of liquid propellants, they provide data as to the statistical reproducibility in seemingly identical experiments, the variations due to test congiguration, etc.

The Thermocouple Grid Analysis method is the most powerful since it directly relates the mixing phenomena and the yield obtained all in one and the same experiment. It is however, considerably more expensive than the others. Instrumentation for high speed monitoring of the individual junctions is expensive and the reduction of the data obtained time consuming.

However, this Thermocouple Grid method is capable of taking measurments in 1iquid propellant mixtures from the start of fallure up to and after ignition. If the grid is extended beyond the original boundaries of the propellant configuration information can be obtained as to fireball growth rate, extent, temperature, shock wave strength, shock wave velocity, etc.

Further and more detailed discussion of these four methods of analysis which can provide the mixing function - time relationship is left to another paper which includes the presentation of results obtained with these methods for a number of failure modes and configurations.

Only one of these results is presented here corresponding to the series of spill experiments used as examples for comparison with the calculated numerical results.

It is the mixing function presented in Fig. 5, in this particular case obtained by method $\mathrm{C}$, the vibration mixing analysis. Since this method has no absolute time scale a number of runs were made adjusting the amplitude and frequency so that easily measurable changes were observed in reasonable time intervals (about 5 seconds). Since from theoretical considerations the maximum should occur at about 7 seconds this time was ascribed to the maximum point of the mixing curve. In this manner the absolute time scale was established.

The reproducibility of this curve as presented was within plus or minus $4 \%$. The reproducibility became better as the mixing violence increased. This fact was observed in all experiments whether simulated on the vibration table or with real liquids using the other methods.

\section{Delay and Detonation Times}

Probably the least understood phenomena of the ones discussed in this paper are the ones controlling the delay and detonation times.

Both these quantities will be discussed in considerable detail in another paper where they are evaluated, and detonation times calculated, based upon a new hypothesis proposed and referred to in that paper as "Firebal1 Hypothesis."

In that paper delay time is defined as the time from the start of the failure to ignition, or the time from start of mixing to ignition, whichever is preferable.

The detonation time is the time from ignition until the reaction reaches the boundary of the original propellant configuration. 
For the purpose of this presentation actually measured delay times from the experiments are taken and statistically analyzed so as to establish the most probable yleld value as well as $95 \%$ confidence limits. More data is needed to establish these quantities with greater reliability. For the test used for comparison here the average delay plus detonation time is 3.3 seconds and the standard deviation for fixing confidence $11 \mathrm{mits} 1.1$ seconds.

Expected Yield Function - Time Relationship (Chart 6)

Having discussed the three groups of phenomena playing a roll in producing the yield of liquid propellant explosions the results obtained in sections I, II, and III can now be combined.

Taking the yield potential function calculated in section $I$ and presented in Fig. 4 and the mixing function calculated in section II and presented in FIg. 5 and combining them by multiplying corresponding ordinates at time $t$, the expected yield function is obtained. This result is presented in Fig. 6 which shows the yield which could be expected at any time $t$ if detonation did occur at that time $t$. Only the curve for the isolated system is presented here but the other is obtained easily in the same manner. This expected yield function has a plus or minus $4 \%$ variation in yield value due to this variation in the mixing function. The expected yield function has a characteristic shape starting at zero increasing with a dip or double hump to a maximum value and then decreasing again. The dip or double hump is due to the initial proportions of the propellant components.

The maximum is far from one since with any appreciable quantity of 1iquid propellants perfect mixing is almost impossible to achieve and furthermore due to the time elapsed between the start of, and best mixing, the yield potential has fallen below one because of evaporation losses of the propellant components.

\section{Expected Yield (Chart 7)}

The last step in this series, to obtain the expected yield for liquid propellant explosions, is to superimpose the information of section III upon the combined results of sections I and II.

Fig. 7 shows the result, the final step in this systematic approach, with the expected yleld function of Fig. 6 modified by the delay and detonation times fixing an interval within which statistically $95 \%$ of a 11 expected yield values should lie.

The highest value for the expected yield predicted for this test series, using $95 \%$ confidence limits, should be about 0.43 , the lowest 0.13 . All values predicted by this approach should fall between 0 and 0.50 .

\section{Closure}

This paper suggested and presented a systematic apporach referred to as the "Seven Chart Approach" for the prediction of expected yields for liquid propellant explosions. The "Seven Chart Approach" consists of seven steps expressible in seven charts:

1. Maximum Theoretical Energy Release

2. Yield Potential as a Function of Oxidizer to Fuel Ratio

3. Mass-Fraction - Time Relationship

4. Yield Potential - Time Relationship

5. The Mixing Function

6. Expected Yield Function Time Relationship

\section{Expected Yield}

The paper presented this approach, outlined here, with actual calculated curves, combined with some experimental results to give quantitative information.

The "Seven Chart Approach" as out1ined above allows for a systematic procedure in determining the expected yield from liquid propellant explosions and thus guides the experimental work necessary to implement the analytical procedures.

This approach divided the problem into three very distinct parts which can be studied separately and when combined give the desired results. The three parts are the determination of the yield potential, the mixing processes analysis, and the ignition and detonation phenomena.

The insight gained into the actual physical phenomena through this approach promises to provide a method of control whereby the hazards from liquid propellant explosions can be considerably reduced.

\section{Acknowled gement}

It is with sincere appreciation that the writers express their indebtedness to the National Aeronautics and Space Administration under whose sponsorship (part of contract NAS10-1255) this work was carried out; to the University of Florida; to G. L. Schoessow, F. I. Schwartz, J. A. Wethington, T. M. Reed, R. L. San Martin, C. Williams and to scientists at MFSC, MSC, NASA Headquarters in Washington, BRL and AFRPL.

\section{Bibliography}

1. Farber, E. A., et al., "Feasibility Study to Explore the Explosive Effects of Liquid 
Propellants to Define the Mathematical Behavior of Physical Processes Involved," Final Report, Phase I, Contract No. NAS10-1255, University of Florida, February 1965.

2. Farber, E. A., "A Mathematical Model for Defining Explosive Yield and Mixing Probabilities of Liquid Propellants," 3rd Space Congress Proceedings, March 1966.

3. Deese, J. H., "A Correlation and Hypothesis of $\mathrm{LH}_{2} / \mathrm{LO}_{2} / \mathrm{RP}-1$ Blast Data," Unpublished, January 1963 .

4. Arthur D. Little, Inc., "Summary Report on a Study of the Blast Effect of a Saturn Vehicle," February 1962.

5. Aerojet-General Corp., "Blast and Fireba11 Comparison of Cryogenic and Hypergolic Prope1lants," Contract No. NAS9-2055, Final Report, 26 June 1964.

6. Mechanical Engineers; Handbook, edited by T. Baumeister, McGraw-Hill Book Co., Inc., 6th Edition, New York, 1958.

7. Obert, E. F., "Internal Combustion Engines," International Textbook Co., Second Edition, Pennsylvania, 1960.

8. Arthur D. Little, Inc., "Summary Report on a Study of the Blast Effect of a Saturn Vehicle," February 15, 1962 and some original data obtained from them.

9. Project Pyro., "Monthly Progress Report Period ending 29 February 1964.

10. Foust, A. S., et al., "Principles of Unit Operations," John Wiley \& Sons, Inc., New York, 1960, p 264.

11. Project Pyro., 'Monthly Progress Report Period ending 31 May 1964," June 9, 1964.

12. Seader, J. D., et a1., "Boiling Heat Transfer for Cryogenics," Final Report, Rocketdyne R-5598, May 11, 1964.

13. ASHRAE Guide and Data Book 1961, American Society of Heating, Refrigeration and AirConditioning Engineers, Inc, 1961.

14. Handbook of Engineering Fundamentals, edited by 0 . W. Eshbach, John Wiley \& Sons, Inc., Second Edition, New York, 1958.

15. Handbook of Chemistry and Physics, edited by C. D. Hodgman, Chemical Rubber Publishing Co., Forty-First Edition, Ohio, 1960.

16. Chemical Engineers' Handbook, edited by J. H. Perry, McGraw-Hil1 Book Company, Inc., Third Edition, New York, 1958.

17. Technical Data on Fuel, edited by H. M. Spiers, The British National Committee World Power Conference, Fifth Edition, London, 1952.
18. Fuels and Combustion Handbook, edited by A. J. Johnson, McGraw-Hi11 Book Company, Inc., New York, 1951.

19. Nelson, W. L., "Petroleum Refinery Engineering," McGraw-Hil1 Book Company, Inc., New York, 1936.

20. Smith, M. L. and Stinson, K. W., Fuels and Combustion, McGraw-Hill Book Company, Inc., New York, 1952 . 


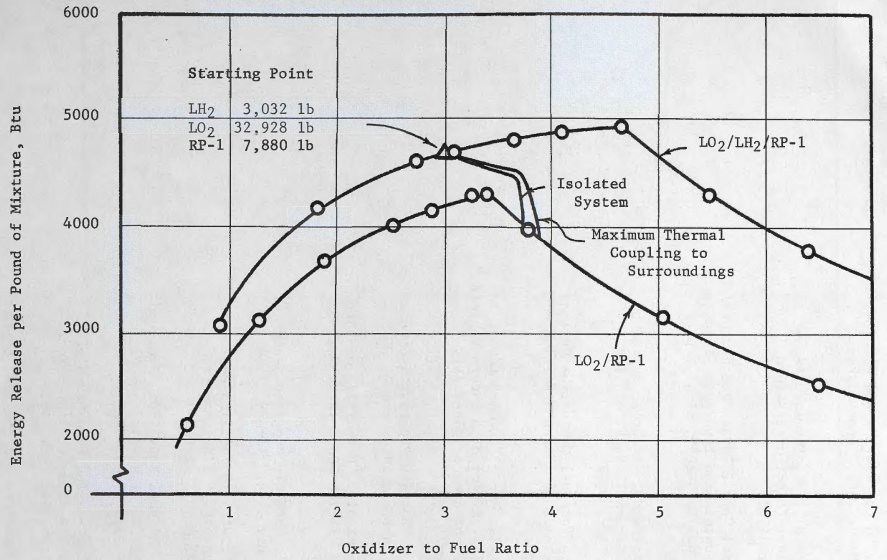

Figure 1A Maximum Amount of Energy Release for a Three Component Liquid Propellant Mixture 


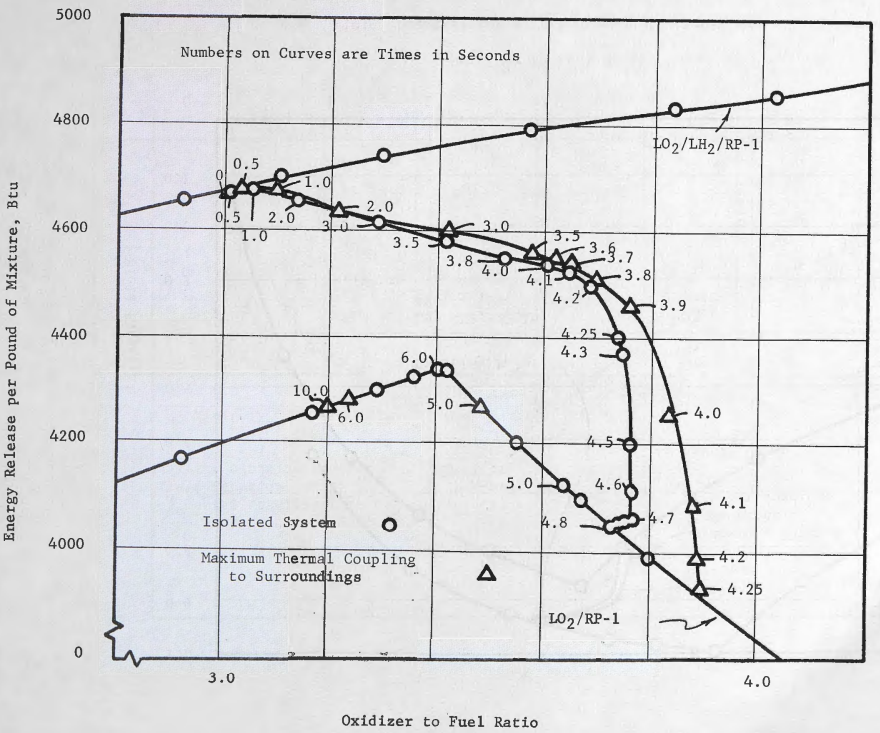

Figure 1B Maximum Amount of Energy Release for a Three Component Liquid Propellant Mixture 


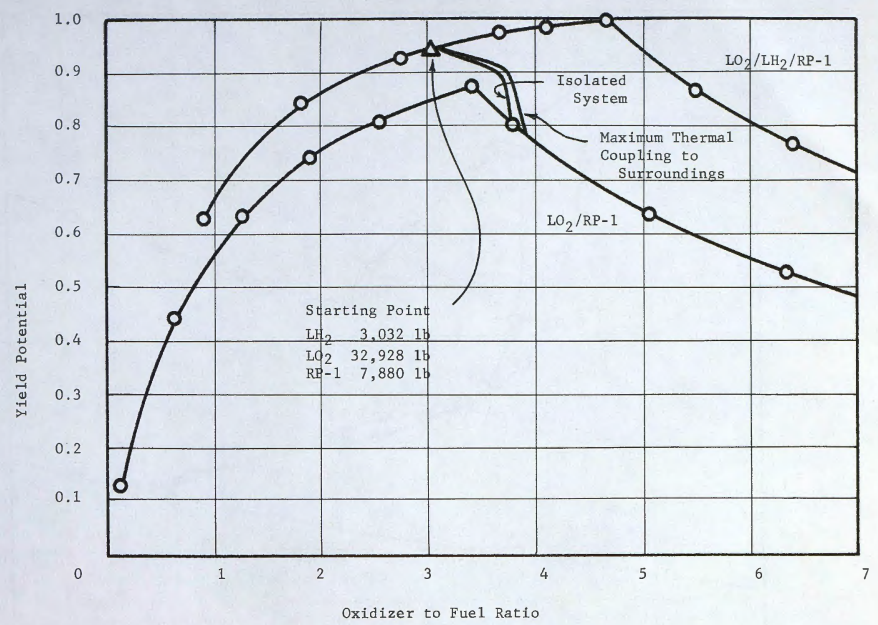

Figure 2 Yield Potential for a Three Component Liquid Propellant Mixture 


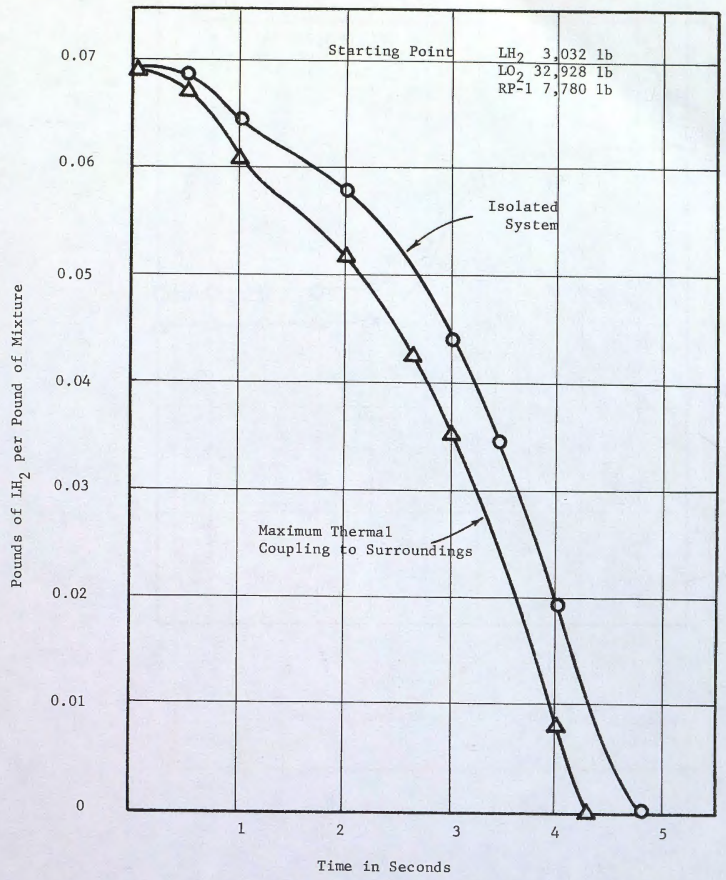

Figure 3A Amount of $\mathrm{LH}_{2}$ Present at Time $t$ 


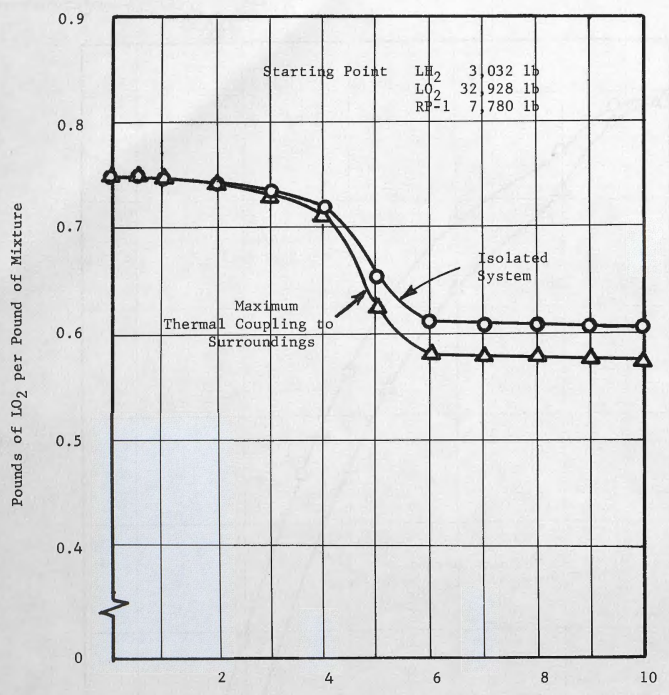

Time in Seconds

Figure 3B Amount of $\mathrm{LO}_{2}$ Present at Time $t$

530 


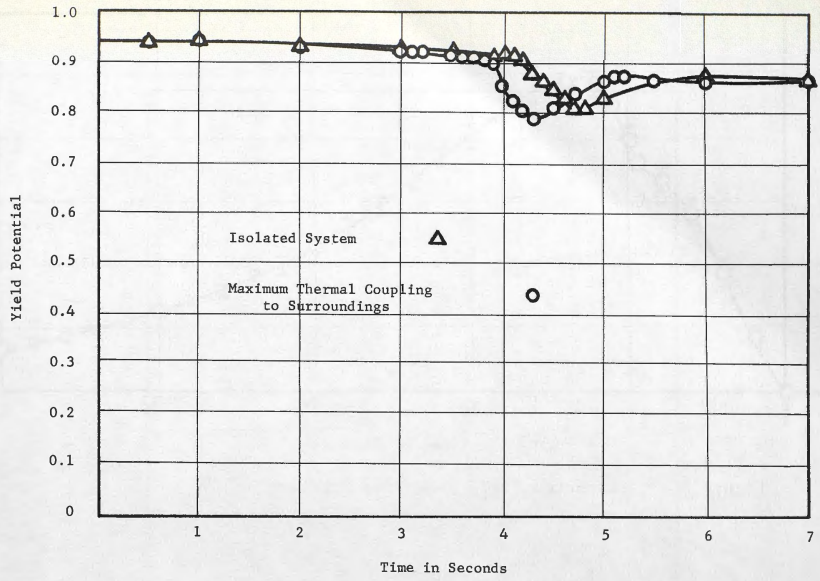

Figure 4 Yield Potential Plotted as Time Function

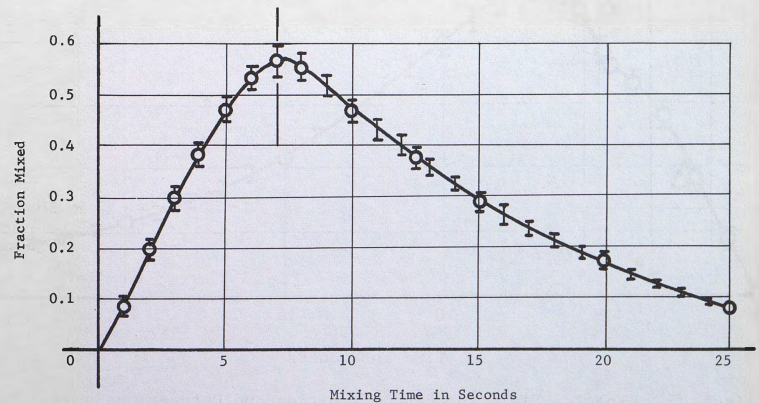

Figure 5 Mixing Function or Spill Function for Three Component Liquid Propellant Spill Tests 


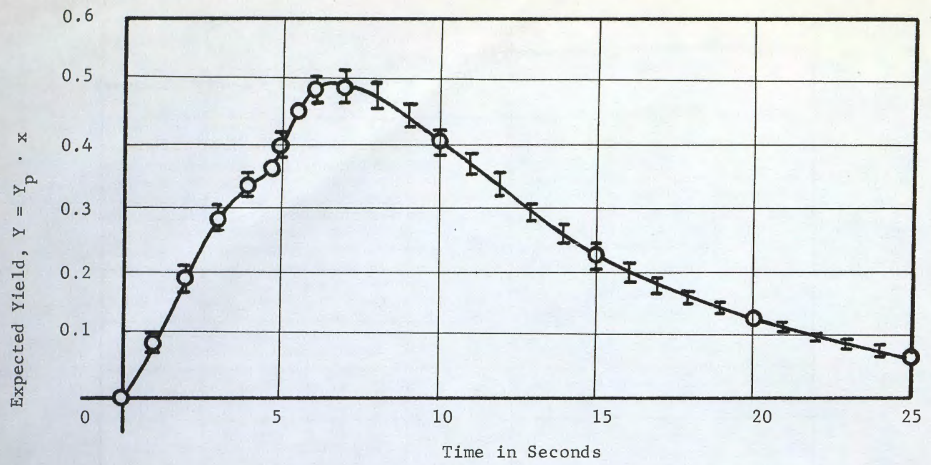

Figure 6 Expected Yield as a Time Function

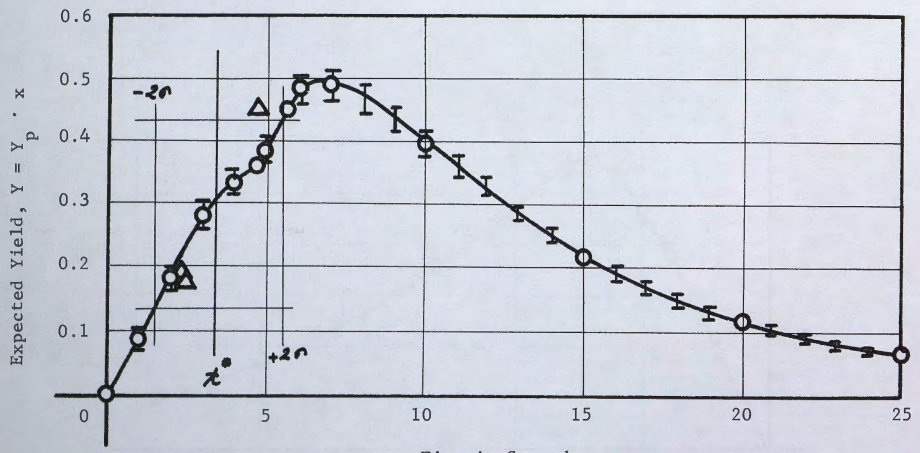

Time in Seconds

Figure 7 Expected Yield for Random Ignition and Detonation Showing the Upper and Lower Limits of the Statistical Confidence Regions for Liquid Propellant Spill Tests 